\title{
The never-ending story
}

\section{A guide to the biggest idea in the Universe: infinity.}

\author{
The Infinite Book: A Short Guide \\ to the Boundless, Timeless and \\ Endless \\ by John D. Barrow \\ Jonathan Cape: 2005. 328 pp. £17.99. To be \\ published in the US by Pantheon Books (\$26). \\ Simon Singh
}

John Barrow is a wide-ranging author. A few years ago he wrote The Book of Nothing (Jonathan Cape, 2000), an exploration of zero, and now he has published The Infinite Book. Again he tackles a subject that has been previously explored by other popularizers of science, but again he brings his charm and wit to bear to provide an account that is highly engaging and enriched with numerous literary references and dozens of illustrations and photographs.

The opening chapters introduce readers to the concept of infinity through the eyes of the various philosophers who tackled the subject through the centuries. Their conflicting views about the nature and existence of infinity are slightly baffling, but the situation is rescued by the nineteenth-century mathematicians who were able to make sense of the infinite realm. What emerges is a series of staggeringly brilliant and beautiful ideas, whose logic and power seem to defy common sense.

For example, are all infinities equal? There are an infinite number of numbers and an infinite number of even numbers, but is the former infinity double the size of the latter, or does infinity have hidden subtleties? The Infinite Hotel is the classic device for addressing this question. Attributed to the German mathematician David Hilbert, the Infinite Hotel is a highly successful enterprise and its infinite number of rooms are fully booked. The situation seems bleak when a new guest turns up at reception, but the resourceful hotelier, comes up with a solution. He asks everybody to move up to the next room - the occupant of room 1 moves to room 2 , the occupant of room 2 moves to room 3 , and so on. This means that everybody still has a room, but room 1 is now empty and is available for the new guest.

This merely shows that infinity plus one equals infinity. But what if an infinite number of new guests arrive at reception? The hotelier asks the current guests to move to the room with the number that is double their current room - the occupant of room 1 moves to room 2, the occupant of room 2 moves to room 4 , and so on. This means that everybody still has a room, but all the odd-numbered rooms are now empty and available for the new guests. So infinity plus

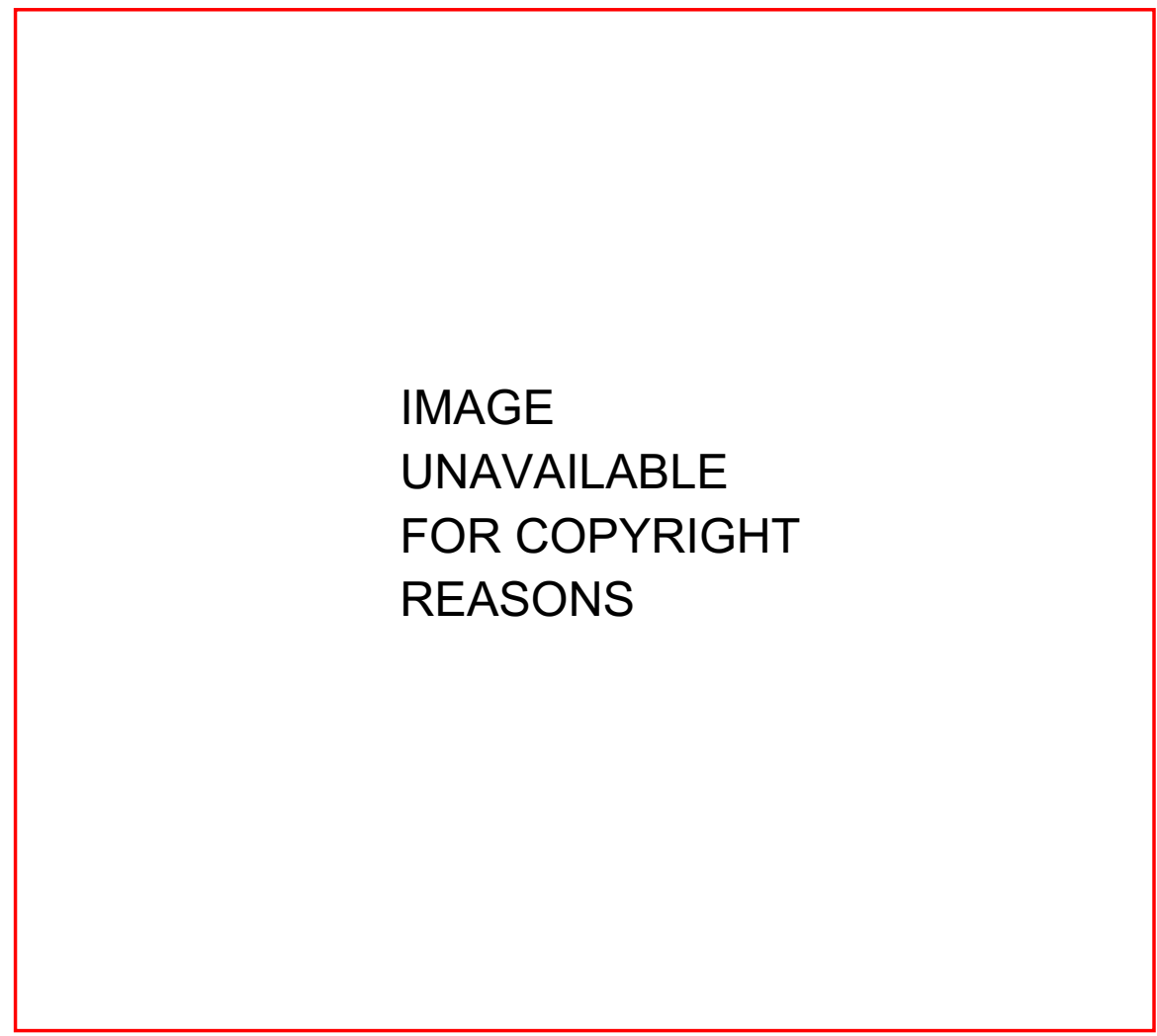

Seeing the big picture: the patterns in Islamic tile designs can be repeated indefinitely.

infinity equals infinity, and hence the number of even numbers is equal to the number of all numbers.

Barrow explains other arguments that show that the number of whole numbers is equal to the number of fractions, but that the number of decimals is larger and represents a different scale of infinity. He also tells the tragic story of Georg Cantor, a German mathematician who developed many of the fundamental ideas relating to infinity. Cantor was heavily criticized by the 'finitists', such as the influential Leopold Kronecker, who successfully vetoed Cantor's applications for senior academic posts and blocked the publication of his papers.

This constant persecution led to a series of nervous breakdowns and spells of severe depression for Cantor, who gradually moved away from mathematics and spent increasing amounts of time with philosophers and theologians. Eventually Cantor did receive some acclaim from mathematicians around Europe, but in his German homeland he was largely ignored. In 1908 he complained that his German colleagues "do not seem to know me, even though I have lived and worked among them for 52 years".

Some chapters move beyond mathematics and deal with the infinitely large in the context of the Universe and the infinitely small with respect to particle physics. Barrow also ventures even further afield, touching on theological issues and examining eternity and the notion of elixirs for immortality.

Occasionally the material feels familiar, but Barrow is generally able to introduce novel twists and turns, and presents standard material in refreshing ways. For example, it is well known that the density at the centre of a black hole is supposed to be infinite, but few people realize that the average density of a large black hole, such as the one at the centre of a galaxy, could be less than the density of air. This is because the Schwarzschild radius of a giant black hole, which defines the point of no return, is so vast.

Familiar characters, such as Hilbert, are also fleshed out in new ways. We learn that one of Hilbert's students committed suicide when he failed to solve a particular mathematical problem. Hilbert was asked to speak at the funeral, so he stood at the graveside and matter-of-factly explained that the problem was not particularly difficult and that the young man had merely failed to look at it in the right way.

Even an old chestnut like the Infinite Hotel feels fresh. This results in an index that lists Fawlty Towers next to Fermat's last 
theorem - surely the only time that these two items have been neighbours in the same book - and this serves to indicate the book's quirkiness.

Simon Singh is the author of Big Bang (Fourth

Estate, 2004), a history of cosmology.

\section{Wine with a deep flavour}

The Winemaker's Dance: Exploring Terroir in the Napa Valley

by Jonathan Swinchatt \& David G. Howell University of California Press. 2004. 243 pp. $\$ 35.95, £ 22.95$

\section{George W. Moore}

The taste of a wine depends on more than just the variety of the grape from which it is made. Winemakers and wine connoisseurs are concerned with terroir (pronounced 'tair-wahr'), which refers to everything else that controls the flavour of wine: climate, subsoil and even the manipulations done in the winery.

Many winemakers believe that the taste of wine comes from the soil that supports the vines. But the soil is only about a metre thick, whereas the roots of the vines extend down about 10 metres or more. The soil is in equilibrium with the local climate: its clay and organic components smooth out the delivery of water to the plants, and cationexchange processes supply major nutrients. But the minor compounds that control the taste come from the much more voluminous subsoil. The bedrock slowly weathers under the action of water, carbon dioxide and organic acids. This process delivers a continuous flux of subsoil-dependent compounds to the vines, and is a key component of the local terroir. In The Winemaker's Dance, geologists Jonathan Swinchatt and David Howell evaluate every aspect of the terroir of a small but well known winemaking region and place their findings in a global context.

The Napa Valley, northeast of San Francisco, is in many ways similar to the famous Bordeaux region of France. They are at similar latitudes on the west coasts of continents, and principally grow the warmclimate grape variety Cabernet Sauvignon. They are both about 50 kilometres from their respective oceans, and large estuaries - San Francisco Bay at Napa and the Gironde at Bordeaux - provide the cool night-time temperatures that preserve the acidity of their premium wines.

The most expensive Napa Valley wines grow on alluvial fans (known locally as 'benches'), which are piles of gravel and interbedded silt that have streamed down off the flanking mountains. At Bordeaux, the counterparts to Napa's alluvial fans are

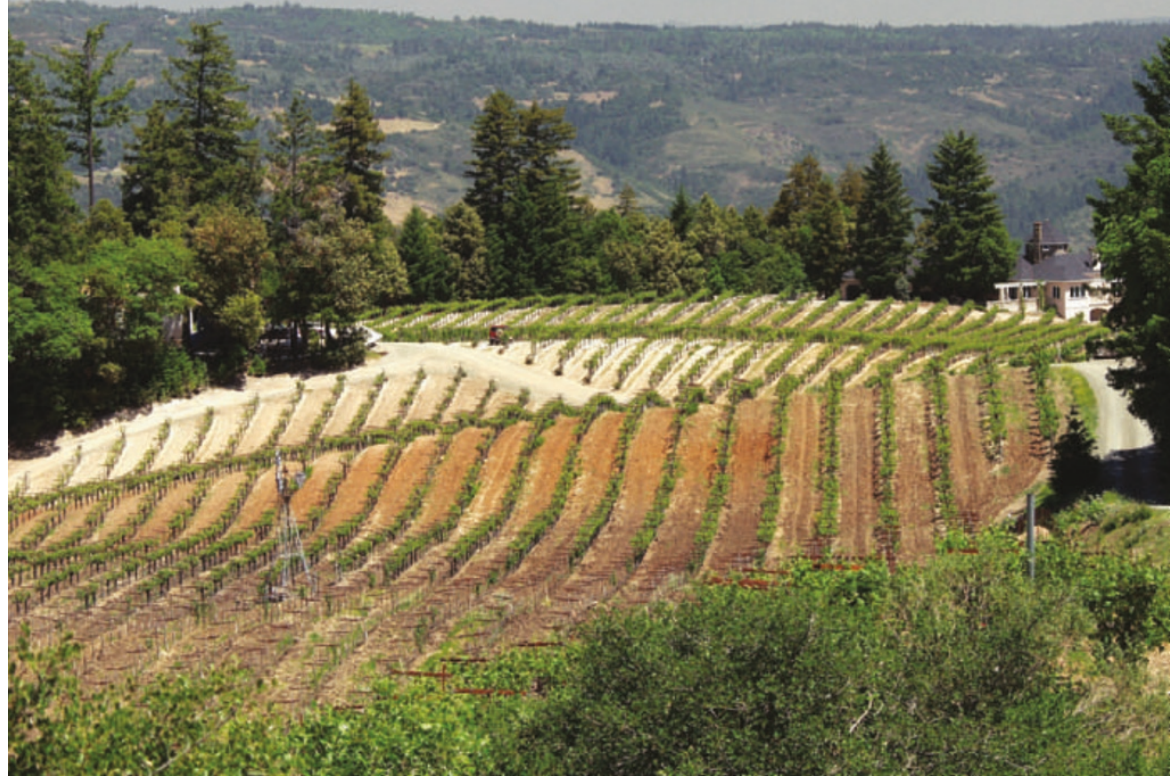

I'm getting something earthy: differences in bedrock can affect both soil colour and a wine's flavour.

the graves (gravel mounds, again interbedded with silt) formed by streams during ice-age low stands of the estuary.

In an effort to link the taste of wine to the subsoil geology, the authors studied Diamond Creek Vineyards, where the vines are planted on upland slopes at the north end of Napa Valley. The 8-hectare property is cut through by a network of faults that juxtaposes three dissimilar geologic blocks. During vineyard development, the owner recognized three strongly contrasting soil colours, and used them to divide the property into three vineyards. These were planted in 1968 with Cabernet Sauvignon cuttings from two first-growth vineyards at Bordeaux.

Throughout its history, Diamond Creek has had three vineyard-designated bottlings. Similar winemaking practices are used for each but the wines consistently taste different. Wine from Red Rock Terrace (which has a basaltic lava subsoil) has velvety tannins with rich cherry and blackcurrant flavours; that from Volcanic Hill (volcanic-ash-bearing sandstone) has tannins that are youthfully firm but long-lived with berry and smoky flavours; and wine from Gravelly Meadow (pebbly stream sediment) has firm tannins with herb, blackberry and earthy flavours.

Two major factors affect the subtleties of wine taste. The first is the 'character' of the wine - the grape variety plus all the elements of its terroir - and the second is the physiology of the people doing the tasting. Tastes vary: one person's crème de la crème is another person's plonk

To investigate the effect of local terroir on the palettes of ordinary consumers, Swinchatt and Howell conducted a blind tasting in 2002, serving eight premium Napa Valley wines with a meal. Most participants ranked the wines differently when they first tasted them to when they tried them again with a meal. When asked which of the eight they preferred overall, the votes were spread quite evenly. In an extreme case of differential preference, one person found the aroma of one wine to be particularly offensive, whereas another said of it: "I'd like to have a bowl of that beside my bed, just to smell."

This variation in personal preference is in marked contrast to the 'expert' opinion of wine-ranking services, which tend to favour blockbuster wines that are extremely intense, particularly on first tasting. This has led to winemakers letting their grapes hang as long as possible on the vines, and extending the time that the wines macerate on the grape skins. Swinchatt and Howell deplore the homogenization that this is causing to the taste of the world's wines. They recommend that consumers ignore the wine-ranking services, seek out diversity, and savour it. George W. Moore is in the Department of Geosciences, Oregon State University, Corvallis, Oregon 97331, USA.

\section{The quantum Universe}

\section{Science and Ultimate Reality: Quantum Theory, Cosmology and Complexity}

edited by John D. Barrow, Paul C. W. Davies \& Charles L. Harper, Jr

Cambridge University Press: 2004. 742 pp. $£ 40, \$ 60$

\section{Frank Close}

In the centenary year of Einstein's seminal contributions to human culture, Science and Ultimate Reality celebrates the 90th birthday of John Wheeler, who took two of Einstein's ideas and created new branches of science. The physics of the twentieth century was built on the twin pillars of Einstein's general theory of relativity and quantum mechanics. The former describes the macroscopic Universe of space-time and gravitation, and the latter is a theory of matter and radiation at subatomic dimensions. These two different 